\title{
A PEDAGOGIA SOCIALISTA COMO POSSIBILIDADE DE SUPERAÇÃO DA PEDAGOGIA TOYOTISTA: CONTRIBUIÇÕES DO MATERIALISMO HISTÓRICO-DIALÉTICO
}

\author{
UNA PEDAGOGÍA SOCIALISTA COMO PEDAGOGÍA TOYOTISTA \\ SUPERACIÓN DE LA POSIBILIDAD: CONTRIBUCIONES MATERIALISMO \\ HISTÓRICO Y DIALÉCTICO
}

\begin{abstract}
THE SOCIALIST PEDAGOGY AS POSSIBILITY OF OVERCOMING TOYOTIST PEDAGOGY: CONTRIBUTIONS OF THE HISTORICAL DIALECTICAL MATERIALISM
\end{abstract}

\author{
Marta Silene FERREIRA BARROS ${ }^{1}$ \\ Dayanne VICENTINI ${ }^{2}$
}

RESUMO: A pesquisa tem como objetivo central problematizar a apropriação da pedagogia toyotista presente em tempos de neoliberalismo pela pedagogia socialista. A partir da relação entre educação e trabalho, podemos analisar que este, inserido no contexto capitalista, acaba por tomar uma forma degradada e alienante. As escolas, configurando-se como instituições formadoras do homem, atrelam-se a concepções pautadas na lógica do mercado de trabalho. Isto é, suas propostas pedagógicas partem do princípio de preparar e treinar os indivíduos para que obtenham perfis adequados às especificidades dos modos de produção fabris da sociedade neoliberal. O percurso metodológico se fez por intermédio de análises bibliográficas de autores que discutem a temática. Vale mencionar, ainda, que o estudo é resultado de discussões realizadas no âmbito do Projeto de Pesquisa FOCO - Formação Continuada: implicações do materialismo histórico e dialético e da teoria histórico cultural na prática docente e no desenvolvimento humano, vinculado ao Programa de Pós-Graduação da Universidade Estadual de Londrina. As análises nos revelaram que é mister lutar para que o modelo educacional vigente dê lugar a uma educação social e humanizadora.

PALAVRAS-CHAVE: Educação. Marxismo. Pedagogia Socialista.

RESUMEN: La investigación se dirige principalmente a discutir la apropiación de la pedagogía Toyotista presente en tiempos de neoliberalismo en la pedagogía socialista. A partir de la relación entre educación y trabajo, podemos analizar esto, se inserta en el contexto capitalista, sólo por tomar una forma degradada y alienante. Escuelas, configurados como centro de formación del hombre, están estrechamente vinculadas a las concepciones que son la lógica del mercado de trabajo. Es decir, sus propuestas pedagógicas asumen preparan y capacitan a los individuos para obtener perfiles adecuados a las características específicas de los métodos de producción industrial de

${ }^{1}$ Docente da Universidade Estadual de Londrina do Departamento de Educação e da Pós Graduação em Educação. E-mail: mbarros_22@hotmail.com

${ }^{2}$ Mestranda do programa de Pós graduação em Educação da Universidade Estadual de Londrina-PR, Professora do Educação Básica do Município de Londrina. E-mail: dayannevicentini@ hotmail.com 
la sociedad neoliberal. La metodología utilizada fue a través del análisis bibliográfico de autores que tratan sobre el tema. Vale la pena mencionar también que el estudio es el resultado de los debates en el proyecto de investigación se centran - Educación continua: implicaciones del materialismo histórico y dialéctico y la teoría histórico cultural en la práctica docente y el desarrollo humano, vinculado al Programa de Graduados la Universidad Estatal de Londrina. El análisis reveló que es necesario en la lucha por el modelo educativo actual da lugar a una educación social y humanizante.

PALAVRAS CLAVE: Educación. El marxismo. Educación Socialista.

ABSTRACT: The research has as a central objective of questioning the appropriation of Toyotist pedagogy present in neoliberalism times, for the socialist pedagogy. From the Relationship Between Education and Labor, we analyze what this, placed in the context of capitalist ends BY Take A degraded and alienating way. How Schools, configured as forming institutions of man, are closely linked to conceptions that are labor market logic. This is, THEIR PROPOSALS educational leave from the beginning to prepare and train individuals to obtain what appropriate profiles at specificities of industrial production modes of neoliberal society. The methodological route was made by authors of literature reviews que discuss the issue. It is worth mentioning also that the study and the results of discussions in Research Project FOCUS - Continuing education: implications of historical and dialectical materialism and historical cultural theory in teaching practice and not human development, linked to the Post Graduate Program from University of Londrina. As analyzes revealed that is needed fight for what the current educational model of a place to education and social humanizing.

KEYWORDS: Education. Marxism. Socialist Pedagogy.

\section{Introdução}

Há muito se discute sobre o papel que a educação desempenha na sociedade e muitas são as concepções que permeiam os debates relacionados à temática. Afinal, é importante questionar quais são as propostas educacionais de formação dos indivíduos na sociedade atual, bem como quais os impactos causados por elas em tempos de neoliberalismo.

Karl Marx, em seus estudos analíticos acerca da história do modelo social, evidencia uma preocupação com a miséria da maior parcela da humanidade, bem como com a exploração do homem pelo homem. Neste sentido, Marx dirigiu seus esforços para a criação de um sistema teórico que teria a "emancipação humana como fim e a revolução como meio" (NETTO; LUCENA, 2016, p.55). O pensador enxergava a educação como um instrumento relevante para a concretização da revolução proletária, que, portanto, deveria ser alcançada ainda na sociedade capitalista. 
Marx, juntamente com Engels, estava atento aos debates educacionais do século XIX sobre a constituição dos sistemas de ensino, que contemplassem a necessidade de instrução dos filhos dos trabalhadores, bem como apresentavam uma conotação de classe que caracterizava a escola capitalista (NETTO; LUCENA, 2016). Vale ressaltar que a educação não era o foco central destes teóricos, mas eles buscavam problematizar o sistema capitalista como um todo, o que abarcaria todas as dimensões sociais, inclusive o campo educacional.

Mas, cabe a indagação: qual seria a especificidade da educação?

Primeiramente, podemos considerá-la como um fenômeno próprio da natureza humana. Diferentemente dos outros animais, o homem possui a capacidade de transformar a natureza, isto é, em vez de ajustar-se a ela, adapta-a a si mesmo por meio do trabalho. Nas palavras de Engels e Marx (1984, p.27), podemos distinguir os homens dos animais "[...] pela consciência, pela religião ou por tudo que se queira. Mas eles próprios começam a se diferenciar dos animais tão logo começam a produzir seus meios de vida".

A categoria trabalho instaura-se a partir do momento em que o indivíduo antecipa mentalmente a finalidade de sua ação. O trabalho então se configura como uma atividade humana intencional (SAVIANI, 2013). Além disso, é uma prática social indispensável para a humanização dos indivíduos. Conforme atuam e transformam a natureza para o suprimento de suas necessidades, os homens, ao mesmo tempo, transformam a si próprios. Tudo o que se produz no trabalho e por intermédio dele é resultado da ação do que poderá se manifestar em característica tipicamente humana, em que carrega a marca das relações sociais que são nesse processo constituídas. Na medida em que o trabalho se insere nos domínios das relações capitalistas de produção, assume forma alienante e deteriorada (NOMA; CZERNISZ, 2010).

Quando tratamos a educação como um fenômeno próprio dos seres humanos significa afirmar que ela é, ao mesmo tempo, uma exigência do e para o processo de trabalho, já que ela própria constitui-se como um processo de trabalho. (SAVIANI, 2013). Podemos dizer, então, que o desenvolvimento do ser humano é resultado de um processo histórico social: ao desempenhar suas atividades por meio do trabalho, ele estará ao mesmo tempo produzindo e se apropriando da cultura.

Ao pensarmos o processo educacional no contexto neoliberal, vemos um ensino atrelado à construção de competências, modelo bastante discutido nos meios da atual educação. Os diversos segmentos, desde o ensino infantil até o superior, são amparados 
por políticas centradas no treinamento dos sujeitos, a serviço da lógica do mercado de trabalho. Isso ocasiona a redução da educação à formação de competências e a adaptação passiva dos indivíduos às exigências do setor mercadológico (MARTINS, 2004).

Neste sentido, a pedagogia toyotista se insere entre as chamadas "pedagogias das competências", primando por uma educação que contribua para a manutenção do status quo da sociedade e pela destituição dos conhecimentos historicamente elaborados pelo homem. Acreditamos que uma alternativa viável de superação desse modelo de ensino estaria pautada em uma educação socialista, em que os conhecimentos podem ser socializados com todos. Para isso, o estudo proposto tem como objetivo problematizar a apropriação da pedagogia toyotista, presente em tempos de neoliberalismo, pela pedagogia socialista.

Para compô-lo, dividimos as discussões em dois momentos. No primeiro, será evidenciado o histórico da relação entre educação e trabalho, bem como a origem da divisão de classes, com o intuito de relevar a importância das bases para entendermos como se deu a historicidade da relação entre homem, trabalho e educação. Isso nos levará a compreender a atual situação entre esta relação na sociedade capitalista. No segundo momento, serão apresentados os pressupostos da pedagogia toyotista e sua problemática, e se buscará realizar uma contraposição entre ela e as práticas pedagógicas da pedagogia socialista.

\section{Relação educação e trabalho: um breve histórico}

O trabalho e a educação são atividades especificamente humanas, isto é, só o ser humano trabalha e educa. Diante disso, Saviani (2007) pondera que o homem é constituído como um ser possuído de propriedades que lhe permitem educar e trabalhar.

Reportando-nos aos primórdios da humanidade e ao processo de surgimento do ser humano, constatamos que do homem surge a necessidade de produzir a sua própria vida. Isto é, diferentemente dos animais que se adaptam à natureza, os homens precisam adaptar a natureza a si, agindo sobre ela e transformando-a conforme suas necessidades. De acordo com Saviani (2007), o ato de agir sobre a natureza e transformá-la em função das necessidades humanas define o que é trabalho. Nas palavras do autor, 
[...] a essência humana não é, então, dada ao homem; não é uma dádiva divina ou natural; não é algo que precede a existência do homem. Ao contrário, a essência humana é produzida pelos próprios homens. O que o homem é, é-o pelo trabalho. A essência do homem é um feito humano. É um trabalho que se desenvolve, se aprofunda e se complexifica ao longo do tempo: é um processo histórico (SAVIANI, 2007, p.154).

Considerando o trabalho como uma essência do homem e como um processo histórico que se complexifica ao longo do tempo, torna-se relevante destacar que se a existência do homem não é garantida pela natureza e não se configura como uma dádiva divina, significa que o homem não nasce homem, mas sua existência é o produto de seu trabalho. Neste sentido, ele se forma como homem. Para que ele se torne como tal, é preciso que aprenda a produzir a sua própria existência. Portanto, a própria formação do homem é um processo educativo.

O processo de produção do homem, desde os seus prelúdios, conduziu à divisão do trabalho e consequentemente à apropriação privada da terra, até então considerada como o principal meio de produção. Isso ocasionou uma ruptura da unidade vigente nas comunidades primitivas, gerando a divisão de classes entre os homens. Desta forma, originaram-se duas classes sociais fundamentais: proprietários e não-proprietários.

Conforme já mencionado, o trabalho é essência do homem; sendo assim, não é possível ao homem viver sem trabalhar. Entretanto, "o advento da propriedade privada tornou possível à classe dos proprietários viver sem trabalhar" (SAVIANI, 2007, p. 154). Com os proprietários tendo em mãos o controle privado da terra onde os homens viviam coletivamente, tornou-se possível viver do trabalho alheio, isto é, do trabalho dos não-proprietários, que passaram ter a obrigação de, com o seu trabalho, sustentar os proprietários donos da terra e a si mesmos. Podemos caracterizar este sistema de trabalho como modo de produção escravista, cujo trabalho é realizado dominantemente pelos escravos.

Segundo Saviani (2007), a divisão de classes também provocou uma divisão na educação, pois, a partir do antigo escravismo, passam a existir duas modalidades de educação: uma destinada à classe proprietária, identificada como a educação dos homens livres, e a outra destinada à classe não-proprietária, compreendida como a educação dos escravos e serviçais. A primeira estaria centrada nas atividades intelectuais, nos exercícios físicos, na arte da palavra e no caráter militar, e a segunda ao próprio processo de trabalho. 
É importante salientar que o modelo de educação dos homens livres, baseado nos conhecimentos intelectuais, lúdicos e militares, deu origem à escola. A partir daí, surge uma forma específica de educação como contraponto àquela inerente ao processo produtivo. Por essa especificidade, essa nova forma de educação passou a ser tratada como a educação propriamente dita, fomentando a separação entre educação e trabalho. Com a divisão dos homens em classes, e a educação também dividida, diferencia-se um ensino destinado à classe dominante e outro voltado à classe dominada.

Com o desenvolvimento do modo de produção capitalista, a sociedade feudal foi se desfazendo, provocando mudanças na própria educação confessional e o Estado na posição central, forja-se a ideia da existência de uma escola pública, universal, obrigatória, leiga e gratuita. Assim, a escola acaba tornando-se exclusivamente responsável pela reprodução do modo de produção capitalista. Saviani (2007, p. 157) salienta que o "desenvolvimento da sociedade de classes, especificamente nas suas formas escravista e feudal, consumou a separação entre educação e trabalho".

A maneira como se organizou o modo de produção possibilitou que a escola se organizasse como um espaço separado da produção, refletindo a divisão entre trabalho manual e trabalho intelectual.

Com o advento do capitalismo, a nova forma social baseia-se no consumo, configurando-se como uma sociedade de mercado. A indústria moderna, no contexto da Revolução Industrial, conduziu a uma simplificação dos ofícios, reduzindo a necessidade de qualificação específica, a maquinaria passou a executar a maior parte das funções manuais, materializando as funções intelectuais no processo produtivo e objetivando a generalização das funções intelectuais na sociedade por parte da escola.

Portanto, a educação burguesa realizou, sobre a base do ensino primário, a divisão dos homens em duas áreas: a das profissões manuais, para as quais se requeria uma formação prática, limitada à execução de tarefas, dispensando-se o domínio dos respectivos fundamentos teóricos; e a das profissões intelectuais, para as quais se requeria domínio teórico amplo, cujo objetivo é o de preparar as elites e representantes da classe dirigente para atuar em diferentes setores da sociedade (SAVIANI, 2007).

E nos dias atuais? Como está constituída a relação entre trabalho e educação? Como a escola, inserida na sociedade capitalista, lida com as práticas pedagógicas? É o que veremos a seguir. 


\section{A educação socialista como superação da pedagogia toyotista}

O principal enquadramento utilizado para definir o sentido da relação entre trabalho e educação no capitalismo contemporâneo é a Teoria do Capital Humano (GENTILI, 2005). Essa teoria pressupõe que os ganhos de produtividade na sociedade capitalista advêm do homem na produção. Seus princípios alcançaram as escolas, por meio da qual gerou-se uma concepção tecnicista sobre o ensino e a organização da educação. Assim, passou-se a disseminar a ideia de que a educação é o pressuposto do desenvolvimento econômico e que ao educar-se o indivíduo estaria valorizando a si próprio, na mesma lógica que se valoriza o capital (MINTO, 2014).

Gentili (2005, p. 49) evidencia que “[...] a promessa integradora da escolaridade estava fundada na necessidade de definir um conjunto de estratégias orientadas para criar condições 'educacionais' de um mercado de trabalho em expansão". A escola então se constituía num espaço institucional que contribuía para a integração econômica da sociedade, formando força de trabalho que se incorporaria ao mercado. Neste sentido, a escola tornou-se um elemento fundamental na formação de capital humano necessário para garantir a capacidade competitiva das economias.

Neste contexto, a pedagogia toyotista ganha um importante papel dentro da sociedade, pautada no atendimento aos interesses da lógica do capitalismo. Kuenzer (2005) nos alerta que esta pedagogia se apropria ao mesmo tempo do ponto de vista do capital e de concepções elaboradas pela pedagogia socialista, buscando salientar os cuidados que devemos ter com estas duas concepções, que, embora tenham os mesmos pressupostos nos discursos e práticas pedagógicas, se diferem em suas ideologias: a pedagogia toyotista busca atender a lógica do capital, enquanto a pedagogia socialista almeja a democratização e a emancipação do sujeito. Para a autora, é necessário estabelecer os limites da pedagogia toyotista, para que se possa avançar de fato na construção de uma pedagogia teórico-prática nos espaços de contradição, isto é, uma pedagogia de fato comprometida com a emancipação humana.

A nova vida social, requerida pelo sistema capitalista, exigiu novas formas de organização do trabalho e, consequentemente, novos comportamentos, valores e atitudes.

O novo tipo de produção racionalizada demandava um novo tipo de homem, capaz de ajustar-se aos novos métodos da produção, para cuja educação eram insuficientes os mecanismos de coerção social; seria 
necessário articular novas competências a novos modos de viver, pensar e sentir, e que fossem adequados aos novos métodos de trabalho caracterizados pela automação, ou seja, pela ausência de mobilização de energias intelectuais e criativas no desempenho das tarefas (KUENZER,2005, p.79).

O modo de trabalho sofre a fragmentação entre a atividade manual e intelectual, ao passo que a escola encarrega-se de materializar esta divisão. Kuenzer (2005) ainda explicita que ela se constitui em um espaço de excelência do acesso ao saber teórico dissociado da práxis, cuja forma de sistematização é elaborada a partir da cultura de uma classe social. Neste sentido, a escola é o fruto de uma prática fragmentada e ao mesmo tempo reproduz esta fragmentação por meio de conteúdos, métodos e formas de organização.

Para que o trabalhador novo atenda às novas demandas do processo produtivo dentro da lógica do capital, a pedagogia toyotista prima pelas "competências" deste novo homem. Em vez de habilidades psicofísicas, esta corrente pedagógica faz alusão ao desenvolvimento de competências cognitivas complexas, porém, sempre visando atender às exigências do processo de valorização do capital.

Kuenzer (2005, p.80) salienta que a nova forma de organização e gestão do trabalho "[...] aparentemente amplia o conteúdo trabalhado ao substituir a linha pela célula de produção, onde um trabalhador cuida de várias máquinas, na verdade esvazia cada vez mais sua atividade", reduzindo os critérios de qualificação e intensificando a força de trabalho, explorando-a cada vez mais. Para a autora, a fragmentação no âmbito do trabalho pedagógico só será possível se vencida a contradição entre a propriedade dos meios de produção e a força de trabalho.

Infelizmente, a prática que se insere no campo pedagógico dentro de uma sociedade de classes desempenha a função de desenvolver subjetividades tais como são demandadas pelo projeto hegemônico, no caso, o capital. Deste modo, o objetivo do projeto pedagógico junto ao processo de trabalho capitalista é o disciplinamento para a vida social e produtiva, em conformidade com as singularidades que os processos de produção vão assumindo.

A pedagogia toyotista, preocupada em atender aos interesses do capital, originou diversas tendências pedagógicas conservadoras no âmbito das escolas tradicional, nova e tecnicista, fundamentando-se sempre na ruptura entre pensamento e ação. A pedagogia referida deu origem a propostas que ora se centravam nas atividades, ora nos conteúdos, sem estar preocupadas com a articulação entre aluno e 
conhecimento, de modo que propiciasse o domínio intelectual das práticas sociais e produtivas.

Com as mudanças econômicas e políticas ocorridas no Brasil a partir dos anos de 1990, as demandas de disciplinamento aumentam e consequentemente as demandas que o capitalismo faz à escola também. Os procedimentos rígidos de produção tornam-se mais flexíveis, e a valorização do capital exige a educação de trabalhadores com novos perfis. Em decorrência, surge uma pedagogia com novos princípios do toyotismo: a pedagogia das competências, que tem por finalidade formar trabalhadores e pessoas com comportamentos flexíveis, para que se adaptem com rapidez e eficiência a novas situações, de modo a serem capazes de criar respostas a situações imprevistas. Este modelo de homem supera a ideia das células de produção, em que alguns trabalhadores devem deixar as máquinas trabalhar e apenas preparar o suficiente para o seu funcionamento. De acordo com Kuenzer (2005), esta superação reforça a ideia de flexibilidade.

Kuenzer (2005, p.78) nos chama a atenção para a

[...] facilidade com que a pedagogia toyotista se apropria sempre do ponto de vista do capital, de concepções elaboradas pela pedagogia socialista, e com isso, estabelece uma ambiguidade nos discursos e nas práticas pedagógicas. Essa apropriação tem levado muitos a imaginar, que a partir das novas demandas do capital no regime de acumulação flexível, as políticas e propostas pedagógicas passaram a contemplar os interesses dos que vivem do trabalho, do ponto de vista da democratização.

A divisão entre os donos dos meios de produção e os que vendem sua força de trabalho acentua-se cada vez mais no regime de acumulação flexível. Desta maneira, ao contrário do que diz o novo discurso do capital, acirra-se a junção entre o trabalho intelectual, que compete a um número cada vez menor de trabalhadores com formação flexível, resultante de uma formação de qualidade, e o trabalho manual, cada vez mais desprovido de conteúdo.

Como forma de sobrepujar a polivalência prescrita nos moldes da pedagogia toyotista, que forma o sujeito para a fragmentação, treinamento e preparo para o mundo do trabalho, surge no cenário educacional uma pedagogia pautada na politecnia, que consiste na articulação entre teoria e prática, isto é, na junção entre trabalho intelectual e manual. Seus princípios baseiam-se em uma nova forma de integração entre diversos conhecimentos por meio de ricas relações que quebram os bloqueios artificiais que 
transformam as disciplinas em compartimentos, fragmentando a ciência. Esta é a essência da educação socialista.

Marx e Engels, ao pensarem um novo modelo de sociedade, entendiam a educação como um meio de superação das injustiças sociais. Dessa forma, acreditavam que ela poderia abarcar três aspectos: educação intelectual, educação corporal - que compreende exercícios de ginástica e militares - e a educação tecnológica. Esta última abrange o caráter científico de todo o processo de produção, ao mesmo tempo em que inicia a criança e o adolescente no manuseio de diversos instrumentos industriais. "Partindo disto, afirmamos que a sociedade não pode permitir que pais e patrões empreguem, no trabalho, crianças e adolescentes, a menos que se combine este trabalho produtivo com a educação" (MARX; ENGELS, 2011, p.85).

Para que tenhamos uma pedagogia verdadeiramente emancipatória, é preciso que ela possua em seu âmago o intuito de superar a contradição entre capital e trabalho,

[...] caso contrário, pode simplesmente vir a corresponder à substituição do trabalhador especializado do taylorismo/fordismo pelo trabalhador multitarefa, o qual nem sempre é criativo e autônomo, mas simples tarefeiro em ações esvaziadas de conhecimento técnico e de compromisso com a transformação, formal e realmente subsumido pelo capital, tal como no toyotismo (KUENZER, 2005.p.81).

Nesse sentido, conforme o pensamento acima descrito, a escola deve estar pautada em uma pedagogia que supere a divisão entre capital e trabalho. A autora elucida que enquanto esta visão não for historicamente superada, infelizmente, não haverá possibilidade de existência de práticas pedagógicas autônomas, mas apenas contraditórias, "cuja direção depende das opções políticas da escola e dos profissionais de educação no processo de materialização do projeto político pedagógico" (KUENZER, 2005, p.90-91).

Para Martins (2004, p.65), a função social da escola é a "[...] socialização do saber historicamente produzido tendo em vista a máxima humanização dos indivíduos”. Essa humanização pressupõe a apropriação de formas de elevação acima da vida cotidiana, pressupõe um processo em direção ao humano genérico. A escola não pode se perder na tarefa de preparar os sujeitos para a produção social e para a produção de si mesmos como seres universais e livres, que estejam preparados para a luta contra a produção social alienada. A libertação dos indivíduos de suas condições opressoras só poderá se dar quando tal emancipação alcançar todos os níveis da consciência. Sendo 
assim, apenas a educação, "[...] a ciência e a extensão do conhecimento, o desenvolvimento da razão, pode conseguir tal objetivo" (MARX; ENGELS, 2011, p.8).

Lenine (1977) defende a necessidade de romper essa alienação capitalista e propõe que as massas sejam educadas com o conhecimento clássico necessário para a sua emancipação, em que trabalho intelectual e material não estariam desvinculados. Esta ainda é a necessidade posta pela prática social e pela prática pedagógica ao professor na contemporaneidade.

Duarte (2001) assevera ser possível uma educação que contemple a autonomia moral e intelectual por meio da transmissão das formas mais elevadas e desenvolvidas do conhecimento existente socialmente.

Deste modo, cabe à educação o papel de intermediar a construção de uma consciência crítica da realidade que esteja apta a implementar ações que busquem a superação da alienação.

\section{Considerações Finais}

A partir deste estudo, podemos considerar que infelizmente a pedagogia toyotista, inserida no campo das pedagogias das competências, permanece ainda muito latente nas propostas e políticas públicas do estado neoliberal. Seus impactos na educação e formação dos sujeitos os transformam em trabalhadores preparados para servir aos interesses do mercado de trabalho, cada vez mais competitivo na sociedade capitalista.

Como alternativa para superar essa educação pautada na lógica de trabalho alienado, conforme aludiu Marx, apresentamos a educação socialista, que propõe uma formação voltada ao processo humanizador dos indivíduos e permite a socialização do saber historicamente elaborado pelo homem, de modo que a classe dominada se aproprie dos bens culturais e compreenda a realidade de maneira concreta, possibilitando sua emancipação.

A educação socialista ainda não está completamente presente nas escolas. O que se sobressai no trabalho pedagógico das instituições de ensino são as pedagogias do "aprender a aprender", que oferecem um ensino cuja função se fundamenta em aspectos técnicos e mercadológicos, para que os indivíduos saiam preparados para atuar em ambientes fabris, conforme propõe a pedagogia toyotista. 
A partir da proposta de implementação de um ensino socialista nas escolas, acreditamos que a educação se transubstanciará em um meio viável para que os sujeitos recebam uma formação integral e emancipadora. Quanto mais os profissionais da área se debruçarem sobre esta perspectiva, mais estarão preparados para compreendê-la em sua essência e desenvolvê-la em sua prática. Deste modo, o estudo sobre essa possibilidade deve se fazer frequentemente presente nas escolas por meio de uma formação continuada que se fundamente nos postulados marxianos, buscando um ensino eminentemente humanizador.

\section{Referências}

DUARTE, N. As pedagogias do aprender a aprender e algumas ilusões da assim chamada sociedade do conhecimento. Disponível em:< http://www.scielo.br/pdf/rbedu/n18/n18a04>. Acesso em: 20 maio 2017.

GENTILI, P. Três Teses sobre a relação trabalho e educação em tempos neoliberais. In LOMBARDI, José Claudinei; SAVIANI, D. ; SANFELICI, J. L. (Org.) Capitalismo, trabalho e educação. Campinas: Autores Associados, HISTEDBR.

KUENZER, A. Z. Exclusão Includente e Inclusão Excludente: a nova forma de dualidade estrutural que objetiva as novas relações entre educação e trabalho. In LOMBARDI, J. C.; SAVIANI, D.; SANFElICE, J. L. (Orgs.) O Capitalismo, trabalho e educação. São Paulo: Cortez, 77-95.

LENINE, V. I. Sobre a educação. Tradução: Eduardo Saló. Lisboa: Seara Nova, v. 2.

MARTINS, L. Da formação humana em Marx à crítica da pedagogia das competências. In: DUARTE, N. Crítica ao fetichismo da individualidade. São Paulo: Autores Associados.

MARX, K. ENGELS, F. Textos sobre educação e ensino. Campinas, SP: Navegando.

MINTO, L. W. Teoria do capital humano. Disponível em: <http://www.histedbr.fe.unicamp.br/navegando/glossario/verb_c_teoria_\%20do_capital _humano.htm>. Acesso em: 19 nov. 2015

NETTO, M. B.; LUCENA, C. A Luta pela Instrução Pública na obra de Marx e Engels. In: OMENA, A.; LIMA, A. B.; LUCENA, C. Trabalho, Estado e Educação: considerações teóricas. Uberlândia: Navegando publicações. 55-82.

NOMA, A. K.; CZERNISZ, E. C. S. Trabalho, educação e sociabilidade na transição do século XX para o século XXI: o enfoque das políticas educacionais. In: Souza, José dos 
Santos; Araújo, Renan. (Org.). Trabalho educação e sociabilidade. 1 ed. Maringá: Editora Praxis/Editora Massoni, v. 01, 193-210.

SAVIANI. D. Trabalho e educação: fundamentos ontológicos e históricos. In: Revista Brasileira de Educação. v. 12 n. 34 jan/abr.

\section{Como referenciar este artigo}

BARROS, Marta Silene Ferreira; VICENTINI, Dayanne. A pedagogia socialista como possibilidade de superação da pedagogia toyotista: contribuições do materialismo histórico-dialético. Revista Ibero-Americana de Estudos em Educação, Araraquara, v. 12, n. 2, p. 1056-1068, 2017. Disponível em: <http://dx.doi.org/10.21723/riaee.v12.n2.9095>. E-ISSN: 1982-5587.

Recebido em: 24/11/2016

Aprovação final em: 17/03/2017 